\title{
CDK4/6 Inhibition
}

National Cancer Institute

\section{Source}

National Cancer Institute. CDK4/6 Inhibition. NCI Thesaurus. Code C116938.

Inhibition of cyclin-dependent kinases 4 and 6 pathway activity to prevent proliferation of cancer cells and tumor growth. 